
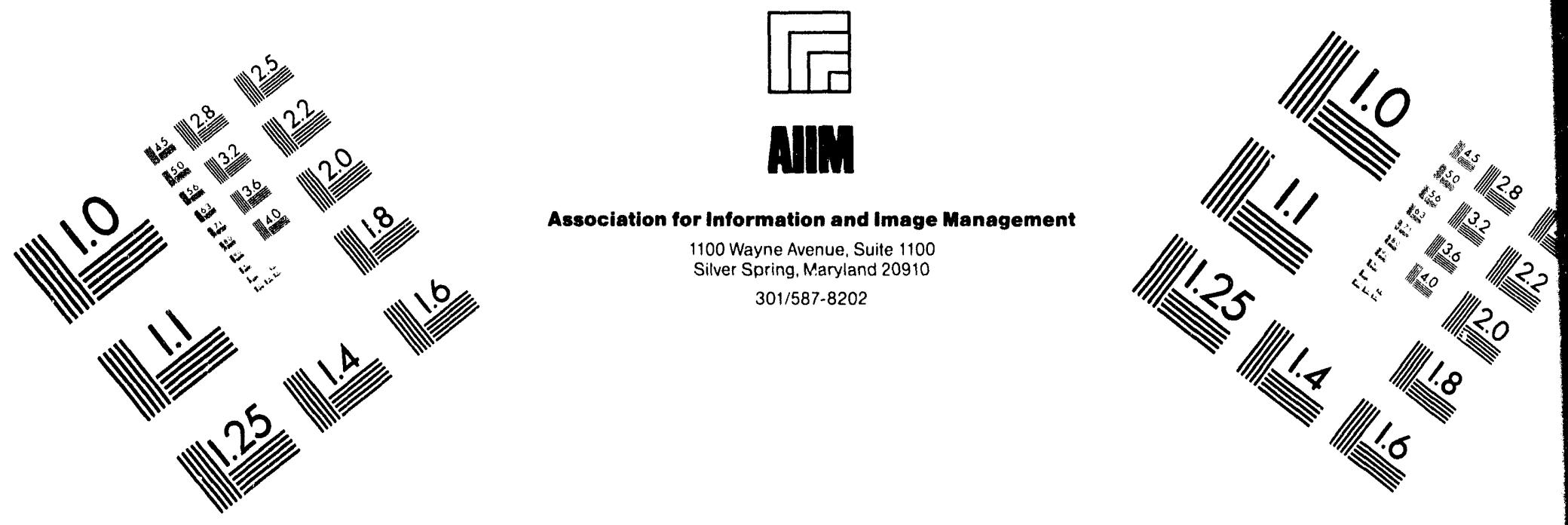

\title{
Centimeter
}

$\begin{array}{llllllllllllllll}1 & 2 & 3 & 4 & 5 & 6 & 7 & 8 & 9 & 10 & 11 & 12 & 13 & 14 & 15 & \mathrm{~mm}\end{array}$ Lm.

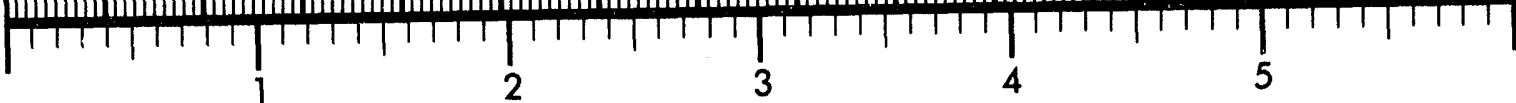
Inches
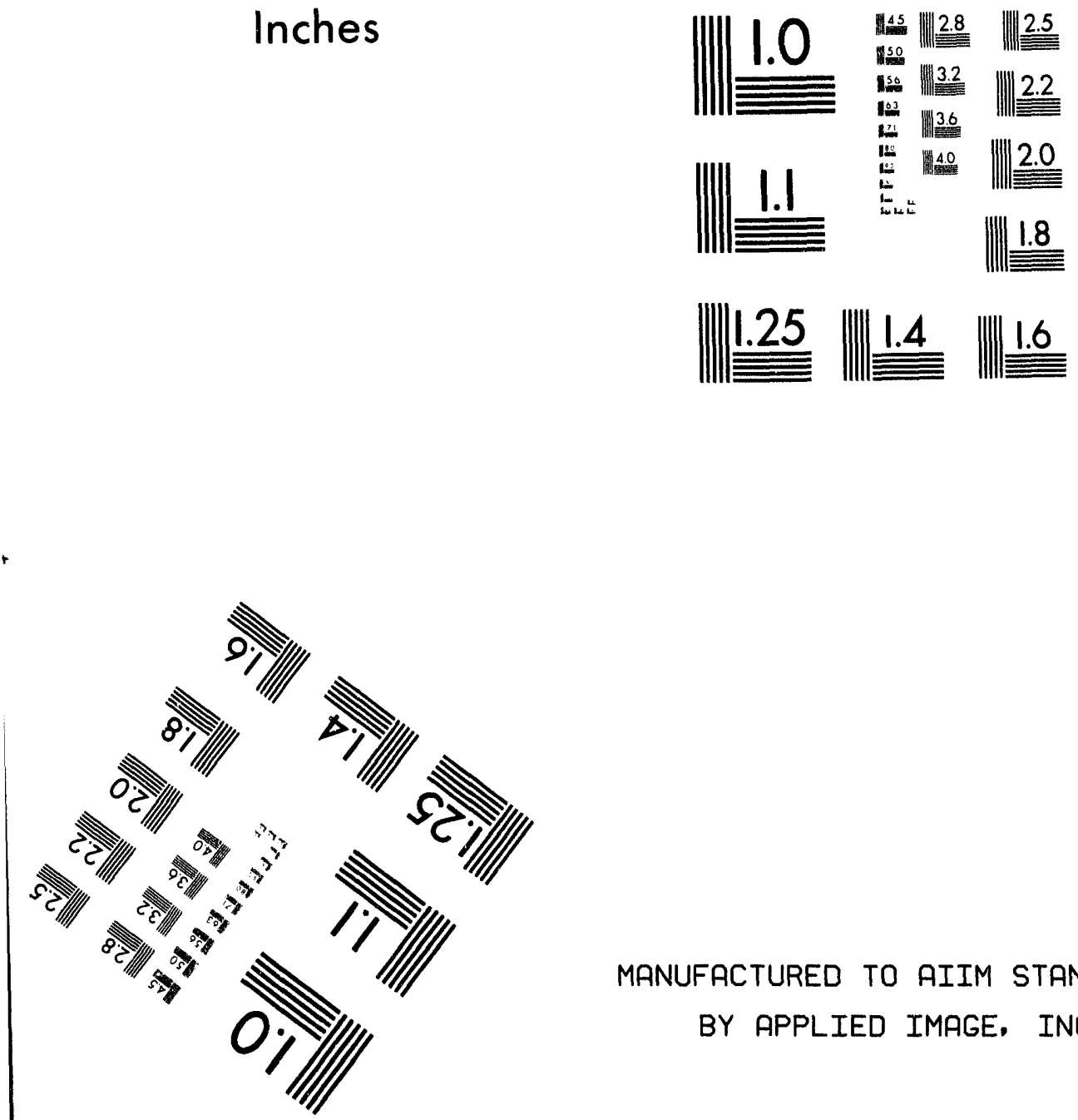

MANUFACTURED TO AIIM STANDARDS

BY APPLIED IMAGE, INC.

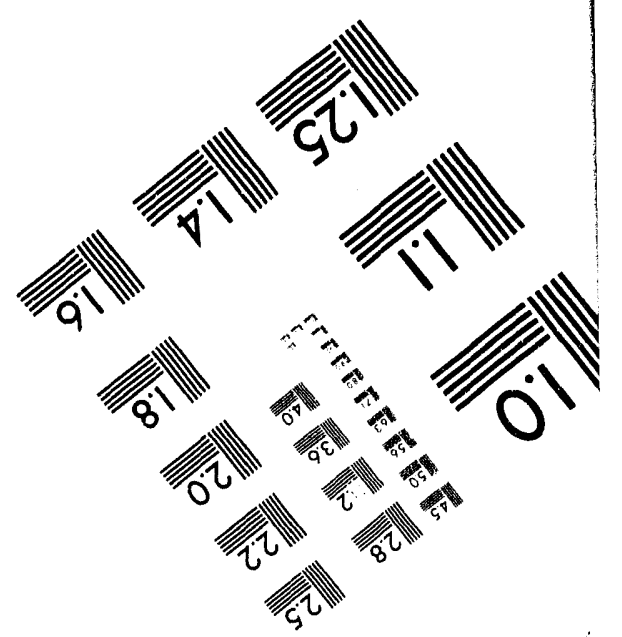



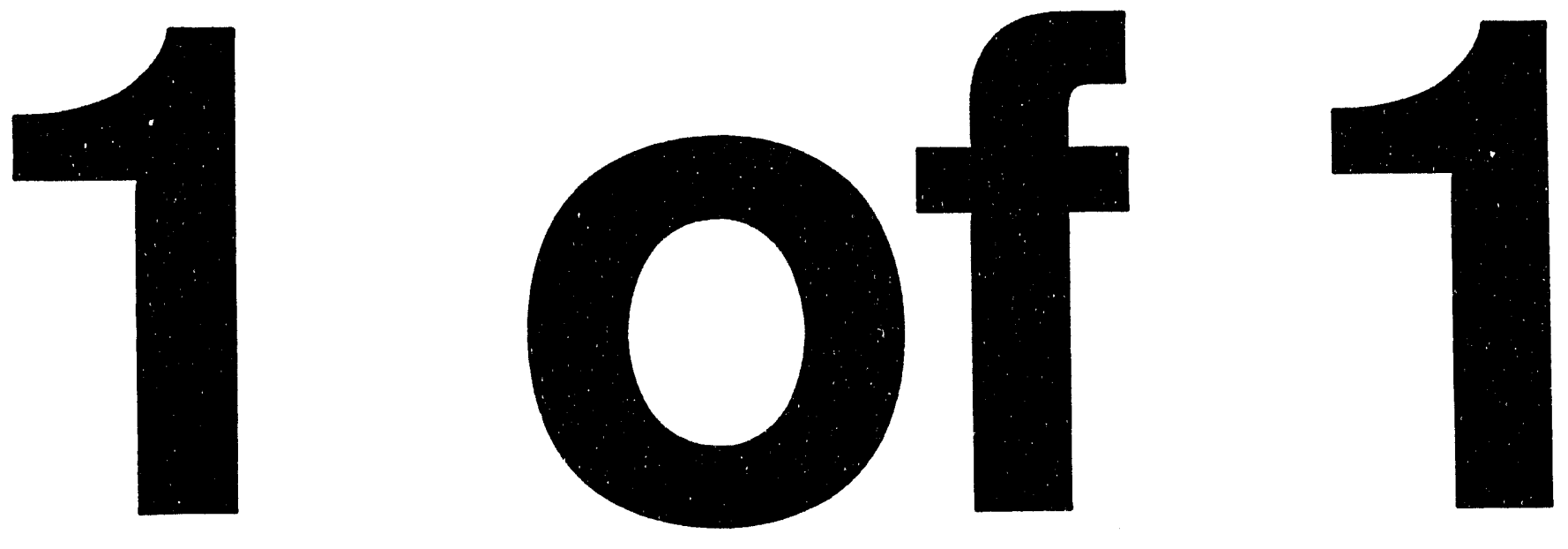


\section{Emittance of Investment Casting Molds}

Mark A. Havstad

RECEIVED SEP 15 1994 OSTI

\section{Lawrence Livermore National Laboratory}

P.O. Box 808, L-470

Livermore, CA 94550

July 15, 1994

This is an informal report intended primarily for internal or limited external distribution. The opinions and conclusions stated are those of the author and may or may not be those of the Laboratory.

Work performed under the auspices of the U.S. Department of Energy by the Lawrence Livermore National Laboratory under Contract W-7405-Eng- 48 . 


\section{DISCLAIMER}

This document was prepared as an account of work sponsored by an agency of the Uniter States Government. Neither the United States Government nor the University of California nor any of their employees, makes any warranty, express or implied, or assumes any legal liability or responsibility for the accuracy, completeness, or usefulness of any information, apparatus, product, or process disclosed, or represents that its use would not infringe privately owned rights. Reference herein to any specific commercial product, process, or service by trade name, trademark, manufacturer, or otherwise, does not necessarily constitute or imply its endorsement, recommendation, or favoring by the United States Government or the University of California. The views and opinions of authors expressed herein do not necessarily state or reflect those of the United States Government or the University of California, and shall not be used for advertising or product endorsement purposes.

This report has been reproduced

directly from the best available copy.

Available to DOE and DOE contractors from the

Office of Scientific and Technical Information

P.O. Box 62, Oak Ridge, TN 37831

Prices available from (615) 576-8401, FTS 626-8401

Available to the public from the

National Techíical Information Service

U.S. Department of Commerce

5285 Port Ruyal Rd.

Springfield, VA 22161 


\title{
Emittance of Investment Casting Molds
}

\begin{abstract}
This document describes measurements of the directional spectral emittance of four ceramic mold materials. The work was performed with the samples at $\sim 900^{\circ} \mathrm{C}$ in a vacuum vessel pumped to $\sim 3$. $\times 10^{-6}$ Torr. The results conform to expectations derived from prior work done with similar samples.
\end{abstract}

\section{Introduction}

The directional spectral emittance of four ceramic samples has been measured between 1.6 and 8.5 microns at angles between $0^{\circ}$ and $80^{\circ}$ (measured relative to a normal to the sample top surface). Sample temperature during the measurements varied between $900^{\circ}$ and $950^{\circ} \mathrm{C}$. This was the highest obtainable with the apparatus at hand. The total hemispherical emittance of the samples has been computed from the measurements using simple fortran computer algorithms.

The samples described here are shells or molds used in the investment casting process and as such influence the cooling rate of such castings. The four samples are labeled FS-seal, FS-stucco, H-seal and H-stucco. Stucco designates a sample with a top surface covered with sand. Seal samples are generally smoother, the grains of sand in them being largely covered by a slurry of material of much smaller grain size.

The hemispherical emissive power from a blackbody at a wavelength $\lambda$ can be written as:

$e_{b}(\lambda, T)=\frac{2 \pi c_{1}}{\lambda^{5}\left(e^{c_{2} \lambda T}-1\right)}$,

where

$$
\begin{aligned}
& c_{1}=0.59544 \times 10^{4} \mathrm{~W} \cdot \mu \mathrm{m}^{4} / \mathrm{cm}^{2}, \\
& c_{2}=14388.0 \mu \mathrm{m} \mathrm{K}, \\
& \lambda=\text { wavelength in } \mu \mathrm{m}, \\
& \mathrm{T}=\text { true temperature of emitting object. }
\end{aligned}
$$

For a "gray" sample, the radiation emitted is decreased by an emissivity factor $\varepsilon$, such that $e(\lambda, T)=\frac{\varepsilon 2 \pi c_{1}}{\lambda^{5}\left(e^{c_{2} \lambda T}-1\right)}$ 
The directional spectral emittance of a surface is defined as the ratio of the emitted light in a given direction at a given wavelength by a non-black (non-ideal) body to that emitted by a blackbody:

$\dot{\varepsilon_{\lambda}}(\lambda, \theta, \varnothing, T)=\frac{\dot{i_{\lambda}}(\lambda, \theta, \varnothing, T)}{\dot{i_{\lambda b}^{\prime}}(\lambda, \theta, \varnothing, T)}$

Where $i_{\lambda b}$ and $i_{\lambda}$ are the radiant intensity from a blackbody and a graybody. The angles $\theta$ and $\varnothing$ are the polar angle and azimuthal angle respectively. The emission from a blackbody does not depend on direction so that

$e_{\lambda b}(\lambda, T)=\pi \dot{\lambda_{b b}}$

For materials whose properties do not depend on azimuthal angle (the vast majority of materials) we drop the $\varnothing$ from the notation

The spectral hemispherical emissivity is obtained from the spectral, directional emissivity by integrating the directional quantity over the $2 \pi$ steradians of solid angle above the sample surface. This integral is written

$\varepsilon_{\lambda, \text { hemi }}(\lambda, T)=\frac{1}{\pi} \int_{0}^{2 \pi} \int_{0}^{\pi / 2} \sin \theta \cos \theta d \theta d \varnothing \cdot \varepsilon(\theta, \lambda, T)$

To obtain total hemispherical emissivity, one must integrate the spectral dependence of the emissivity over the entire wavelength spectrum using proper weighting with Planck's distribution function to account for the influence of sample temperature. This integral is written

$\varepsilon_{\text {tot. hemi }}(T)=\frac{\int_{0}^{\infty} e_{b}(\lambda, T) \varepsilon_{\lambda, \text { hemi }}(\lambda, T) d \lambda}{\int_{0}^{\infty} e_{b}(\lambda, T) d \lambda}$

The presence of the temperature, $\mathrm{T}$, in the blackbody emissive power equation causes spectral emissivity data, which may be very nearly or even totally temperature independent, to yield total emissivity results that are significantly temperature sensitive. Such is the case here.

Assuming the spectral directional emittance to be entirely temperature independent, one can rewrite the result for total hemispherical emissivity as

$\varepsilon_{\text {tot. hemi }}=\frac{2 \pi c_{1}}{\sigma T^{4}} \int_{0}^{\infty} \frac{\varepsilon_{\lambda, \text { hemi }}(\lambda) \mathrm{d} \lambda}{\lambda^{5}\left(\mathrm{e}^{c_{2 \lambda \mathrm{T}}}-1\right)}$ 


\section{Description of the Apparatus}

Small mold samples $(\sim 0.5 "$ diameter) were directly mounted to 50 watt resistance heaters. A tungsten-rhenium (W-5\%Re/W-26\%Re) thermocouple was bonded to the side of the sample. The heater, sample and thermocouple assembly was mounted on a rotary feedthrough in a vacuum vessel. This assembly is shown in Figure 1. The feedthrough attachment is on the left. Wires for the heater and thermocouple extend to the right. Behind the sample, the screen which protects the turbomolecular pump from debris, is visible. The photograph is a view through a quartz port attached to the side of the vacuum vessel. A second viewport (made of $\mathrm{CaF}_{2}$ ), not shown, is mounted directly above the sample. Some of the emission from the hot mold material which passes through this upper viewport strikes a turning mirror and is directed to a focusing mirror. This second mirror images the sample upper surface at a photodetector (see Figure 2). An optical chopper and bandpass filters are located between the focusing mirror and the detector to permit use of phase sensitive detection and to control the wavelength range of individual measurements, respectively.

For each sample investigated, two sets of measurements were made. First, a sample was loaded, as described above, but with a small patch of the sample top surface coated with aerodag (a colloidal suspension of fine graphite particles). This portion of the top surface served as a reference emitter (the emittance of carbon black is a well studied quantity) so that the normal spectral emittance of the mold material could be established relative to the aerodag.

The emittance of the sample relative to aerodag is obtained by translating the detector across the image of the sample (see Figure 2). The aperture at the detector (diameter $1.45 \mathrm{~mm}$ ) selects the region from which sample emission is collected. When the detector is translated to put the aerodag patch over the aperture, a higher signal is obtained, for the elevated emissivity of the aerodag.

For other portions of the sample surface, the detector signal is lower and nearly constant. When the edges of the sample are imaged at the detector aperture, the sample signal declines because the edges are cooler than the sample center. Estimated thermal profiles of mold samples on heaters were given in an earlier report 1 .

At a single wavelength, the normal spectral emittance is obtained from three recorded signals, $\mathrm{I}_{\text {sam }}, \mathrm{I}_{0}$ and $\mathrm{I}_{\text {Aero: }}$

$\varepsilon(\lambda, T)=\frac{\left(I_{\text {sam }}-I_{0}\right)}{\left(I_{\text {Aero }}-I_{0}\right) / \varepsilon_{\text {Aero }}}$

The signals from the sample and the aerodag, described above, are $\mathrm{I}_{\text {sam }}$ and $\mathrm{I}_{\text {Aero }}$ respectively. The signal recorded with an aerodag coated cardboard card over the top viewport is $I_{0}$. This is a type of null signal which is negligible for most of the measurements (see Larrabee ${ }^{2}$ for a full description of $\mathrm{I}_{0}$ ). The emissivity of aerodag ( $\varepsilon_{\text {Aero }}$ $\simeq 0.85$ ) corrects the denominator to represent blackbody emission.

Using a reference emitter to obtain the normal spectral emittance is common though inferior to the integral blackbody cavity technique. With this method a hole is drilled into a portion of the sample surface. For a hole internal area much greater than cross sectional or opening area and a blackening agent deposited on the hole walls, one approximates blackbody (or Planck function) emission from the cavity. This method is often capable of lower 
systematic errors than the reference approach but here the cost and complexity of drilling the extra cavity for the blackbody emission were judged to be too great. Errors incurred due to use of the reference emitter approach will be discussed later.

Directional spectral emittance measurements (off normal emission) were obtained similarly but the aerodag patch was not applied to the sample surface. The optical system was the same. The top center of the sample was imaged at the detector and for each wavelength of measurement the signal at the detector was recorded as the sample/heater assembly was rotated. Detector output voltage was recorded for emission from $0^{\circ}, 15^{\circ}, 30^{\circ}, 40^{\circ}, 50^{\circ}, 60^{\circ}$, $70^{\circ}$ and $80^{\circ}$. As before, the null signal was recorded at each wavelength. These measurements were then used in conjunction with the normal emittance data to give the directional spectral emittance for each of the four samples and for wavelengths from 1.6 to $8.5 \mu \mathrm{m}$.

\section{Results}

The results for directional spectral emittance are shown in Figures 3, 4, 5 and 6 . Figures 3 and 4 give the results for $\mathrm{H}$-stucco and $\mathrm{H}$-seal respectively. The lines shown are polynomial fits to the points shown. It is the polynomials which are used in the integral computations to obtain the total hemispherical emittances given in Table 1. The points shown at $90^{\circ}$ in all four plots are of course not data but are input to the fitting calculations. Electromagnetic theory dictates that the emittance be zero at $90^{\circ}$. The dependence of the results on wavelength is not readily explained. In general we expect emittance increasing with wavelength for a ceramic (in the 1 to $8 \mu \mathrm{m}$ range). In spectral regions where aluminates and silicates are highly absorbing we expect high emittance.

Figure 5 and 6 give the results for FS-stucco and FS-seal respectively. The results are similar to those shown in Figures 3 and 4. The simple polynomial approach is less suited to the higher emittance (at some wavelengths) of the FS-seal but a more complex approach was not worth the effort given the precision of the measurements (see comments on errors below).

The polynomial fits to the angular results (one fit for each wavelength of each material) were integrated numerically (Equation 5) to give the hemispherical spectral emittance of each of the four materials. These results were then fit with a simple second order polynomial fit (one fit for each material). This last polynomial had a limited range of validity, in contrast to first set of polynomials which were valid from $0^{\circ}$ to $90^{\circ}$. The hemispherical fits were valid between 2 and $8 \mu \mathrm{m}$. Constant values of hemispherical spectral emittance were used outside of these bounds in the numerical integration scheme (a FORTRAN version of Equation 7). Results of these integrations are given in Table 1.

\section{Discussion}

The data presented here is qualitatively similar to that obtained from samples reported earlier ${ }^{1}$ and that reported for assorted ceramic samples in property surveys ${ }^{3}$. For this reason moderate confidence in the results in warranted despite two concerns discussed below.

All measurements suffer from systematic and random error. Random errors are readily treated and will be discussed below. Systematic errors can be difficult to detect and quantify. In my opinion, two causes of systematic error may cause the results reported here 
to be inaccurate by more than $25 \%$ of the reported value. First, there may be transmissive effects. If the emitted light from the hot mold (collected by the optical system) originates from millimeter or greater depths in the sample then the emittance results may be erroneously high. The sample interior is hotter than the exterior so that with transmission effects the surface signal recorded $\left(\mathrm{I}_{\text {sam }}\right)$ may be biased towards higher temperatures. No comparable transmissive effects are present from the aerodag coated reference surface. If the samples are highly transmissive some of the measured emission may come from the top of the heater (a very hot surface). This is an extreme and unlikely possibility but it illustrates the concern: The measured emittance may be elevated over the true surface emittance (but actually may be a value more representative and suited to the cooling conditions of castings). If transmissive effects are present as castings cool then radiant heat loss will be enhanced over simple surface emission. We intend to quantify transmissive effects in future work.

The second possible systematic error arises from the use of the aerodag reference emitter. The aerodag's higher emittance may cool the sample surface locally causing a lower than true reference signal to be recorded by the measurement system. This possibility would cause the reported emittance to be higher than the actual value. However, it is unlikely that this type of error is significant for two reasons. First, the size of the aeordag patch was kept to a minimum ( $-3 . \mathrm{mm}$ in diameter) and the present results are similar to those reported earlier, where a different measurement procedure was employed. As with the prior concern, this one can be quantified by more detailed work on the transmissive properties of the materials.

Random errors have been estimated by perturbing the measured signals and repeating the data reduction. Since the measured signals (voltages from the photodetector/lock-in amplifier system) could be reliably read to better than 0.01 volts, the perturbation selected was a 0.01 increase to all the sample signals recorded and a 0.01 decrease to all the reference emitter signals recorded (for all the data for the FS-seal material). Both of these perturbations cause an increase in the computed emittance so together they should estimate an upper limit to the measurement uncertainty due to random errors. When both the directional and spectral integrations are performed with the perturbed signals as input, the total hemispherical emittance changes by approximately ten percent.

Results of the perturbation are given in Table 2. This estimate of random error is conservative for most of the data but it does not quantify systematic error. Errors in measurement angle are also ignored here. These are expected to be small because the rotary feedthrough position was easily read to better than $1^{\circ}$ and for most of the work emittance was changing very slowly with angle.

\section{Conclusions}

The total hemispherical emittance of four casting molds has been reported. Random errors are estimated to be less than $\pm 10 \%$ but concerns regarding systematic errors persist. Sample transmission may be a significant aspect of casting cooling as well as a source of error to the measurements reported here. Measurements of optical transmission through thin samples of mold material at elevated temperatures is planned to address these concerns. 
Table 1

The Hemispherical Total Emittance of Four Mold Materials

\begin{tabular}{|c|c|c|c|c|}
\hline Temperature & $\begin{array}{c}\text { FS-Seal } \\
(-)\end{array}$ & $\begin{array}{c}\text { FS-Stucco } \\
(-)\end{array}$ & $\begin{array}{c}\text { H-Seal } \\
(-)\end{array}$ & $\begin{array}{c}\text { H-Stucco } \\
(-)\end{array}$ \\
\hline 600 & 0.6 & 0.46 & 0.53 & 0.55 \\
\hline 800 & 0.55 & 0.47 & 0.54 & 0.47 \\
\hline 1000 & 0.49 & 0.47 & 0.54 & 0.4 \\
\hline 1200 & 0.44 & 0.46 & 0.54 & 0.35 \\
\hline 1400 & 0.39 & 0.44 & 0.54 & 0.31 \\
\hline
\end{tabular}

Table 2

Perturbed and Unperturbed Results for the Hemispherical Total Emittance of FS-Seal

\begin{tabular}{|c|c|c|c|}
\hline $\begin{array}{c}\text { Temperature } \\
(\mathbf{K})\end{array}$ & $\begin{array}{c}\varepsilon_{\text {hemi, tot }} \\
\text { (as } \\
\text { measured) }\end{array}$ & $\begin{array}{c}\varepsilon_{\text {hemi, tot }} \\
\text { (perturbed } \\
\text { signals }\end{array}$ & $\begin{array}{c}\% \\
\text { Change (-) }\end{array}$ \\
\hline 600 & .60 & .54 & 10. \\
\hline 800 & .55 & .49 & 11. \\
\hline 1000 & .49 & .44 & 10. \\
\hline 1200 & .44 & .39 & 11. \\
\hline 1400 & .39 & .35 & 10. \\
\hline
\end{tabular}




\section{References}

1. UCID-21385, M.A. Havstad, "Directional Spectral Emissivity Measurements on a Ceramic Mold Material", (1988)

2. R.D. Larabee, "Spectral emissivity of Tungsten", J. Optical Society of America, 49, 619 (1959)

3. Y.S. Touloukian and D.P. DeWitt, "Thermal Radiative Properties", Volume 7 of Thermophysical Properties of Matter, IFI/Plenum, New York (1970) 


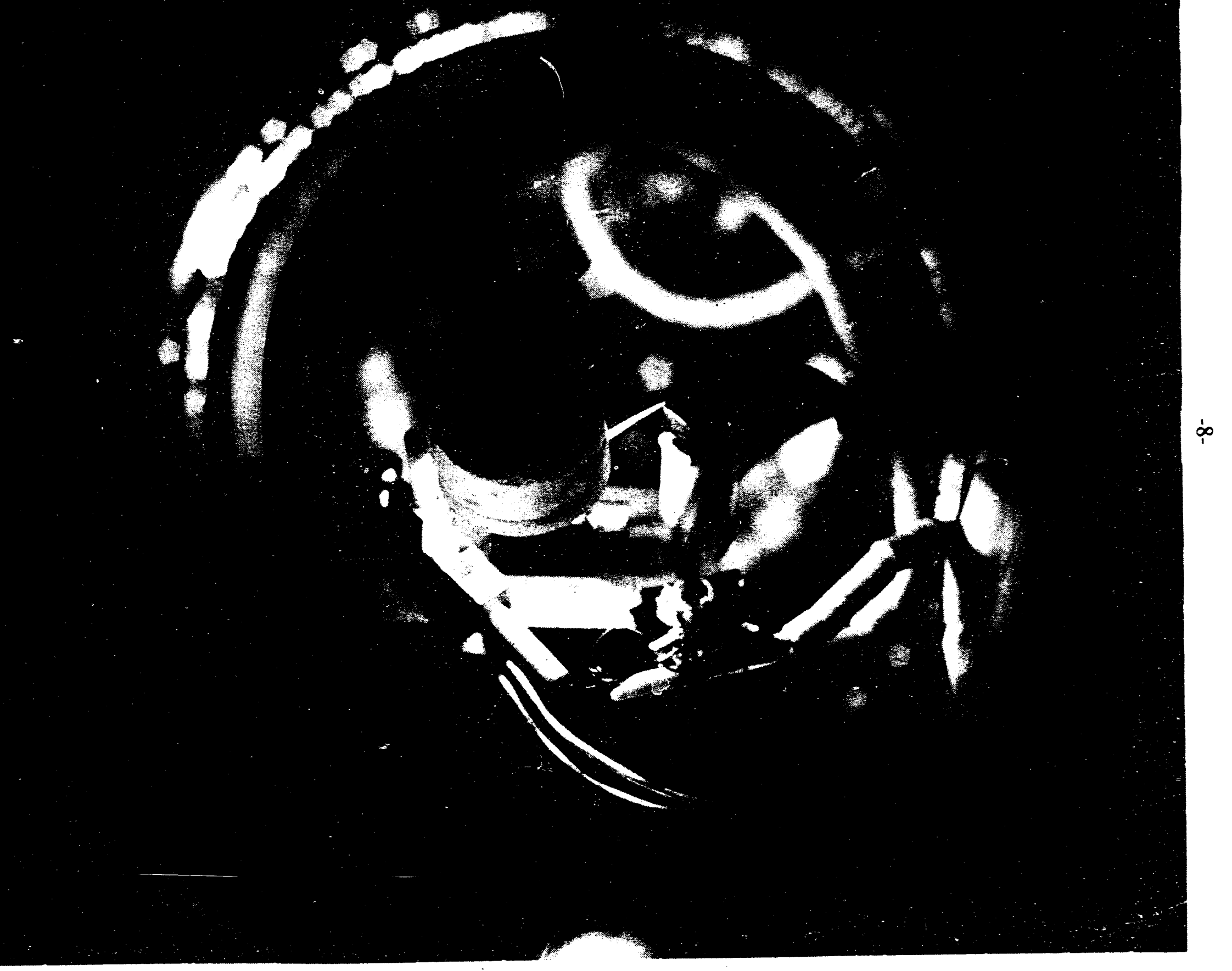




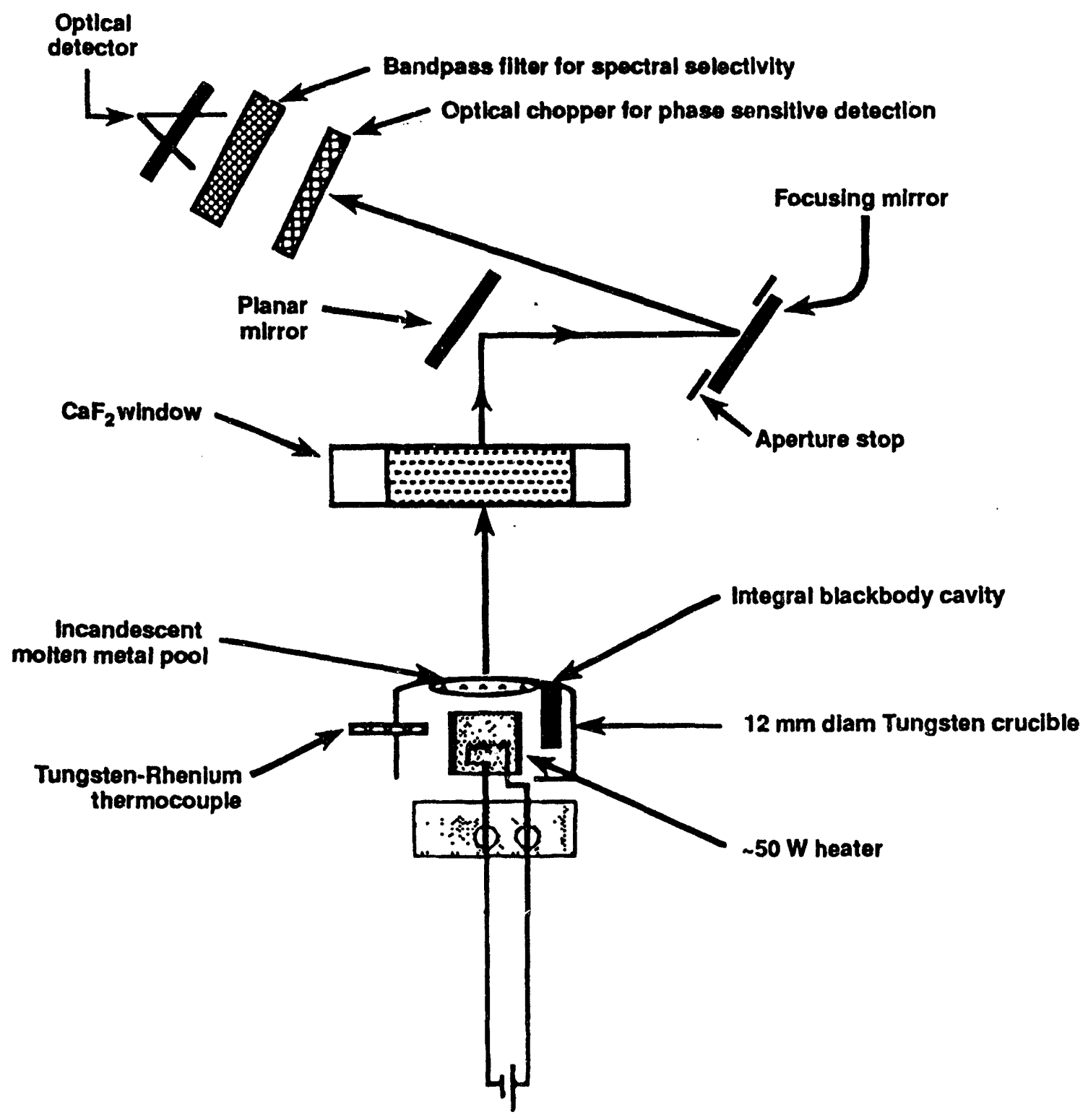

Figure 2. Schematic of the apparatus for measurements of normal spectral emissivity. 


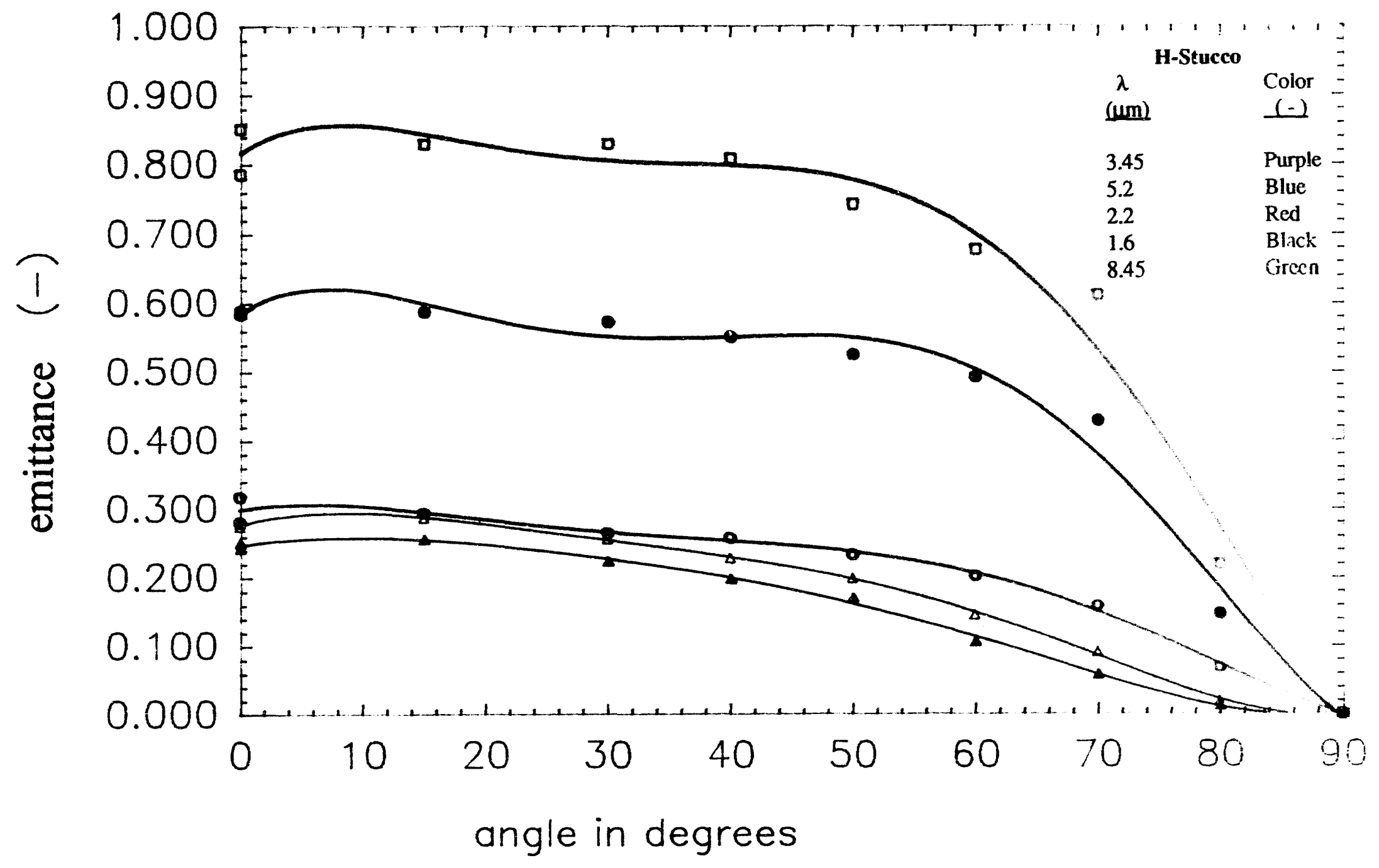

Figure 3. H-stucco directional spectral emittance. 


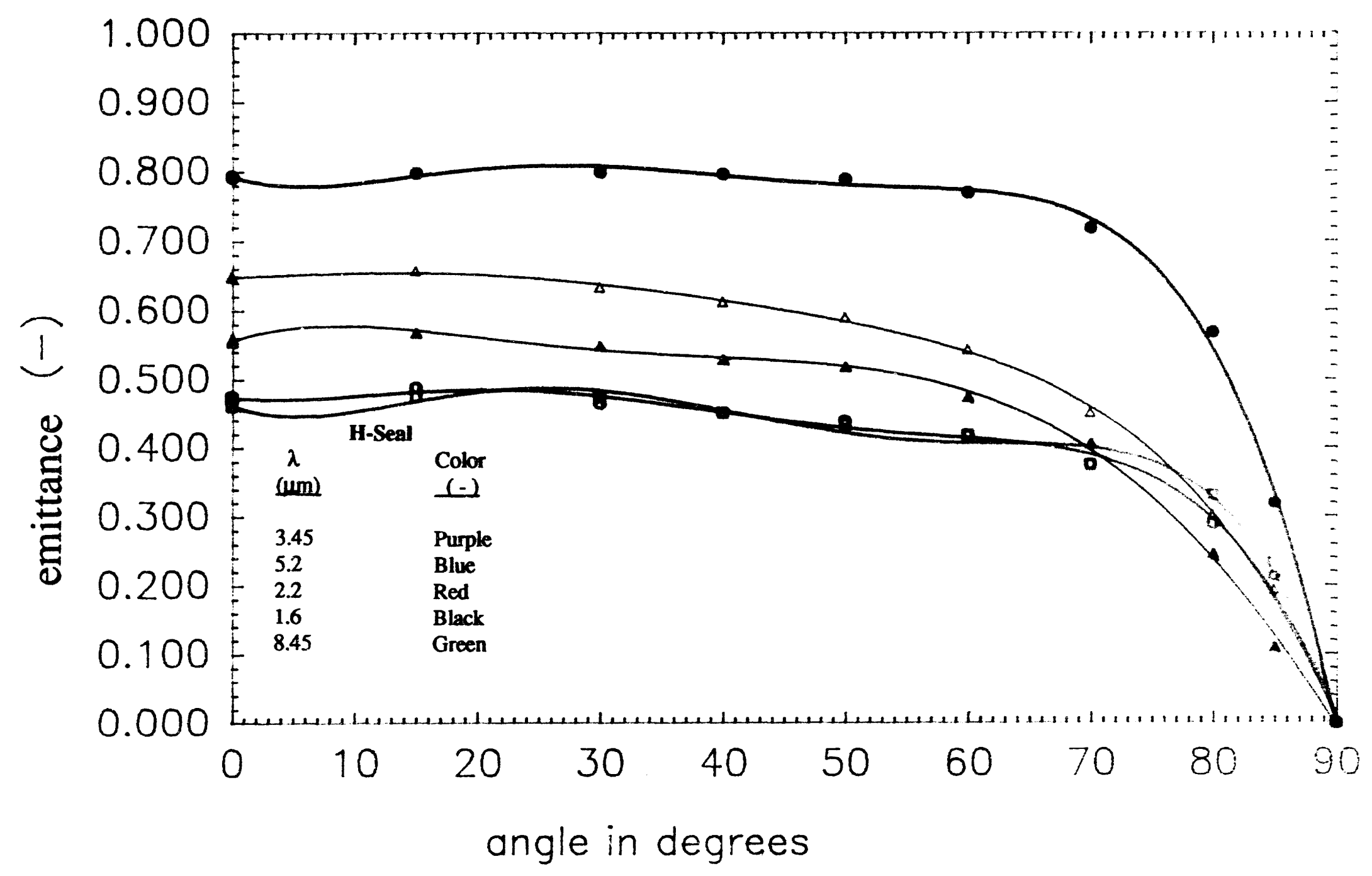

Figure 4. H-seal directional spectral emittance. 


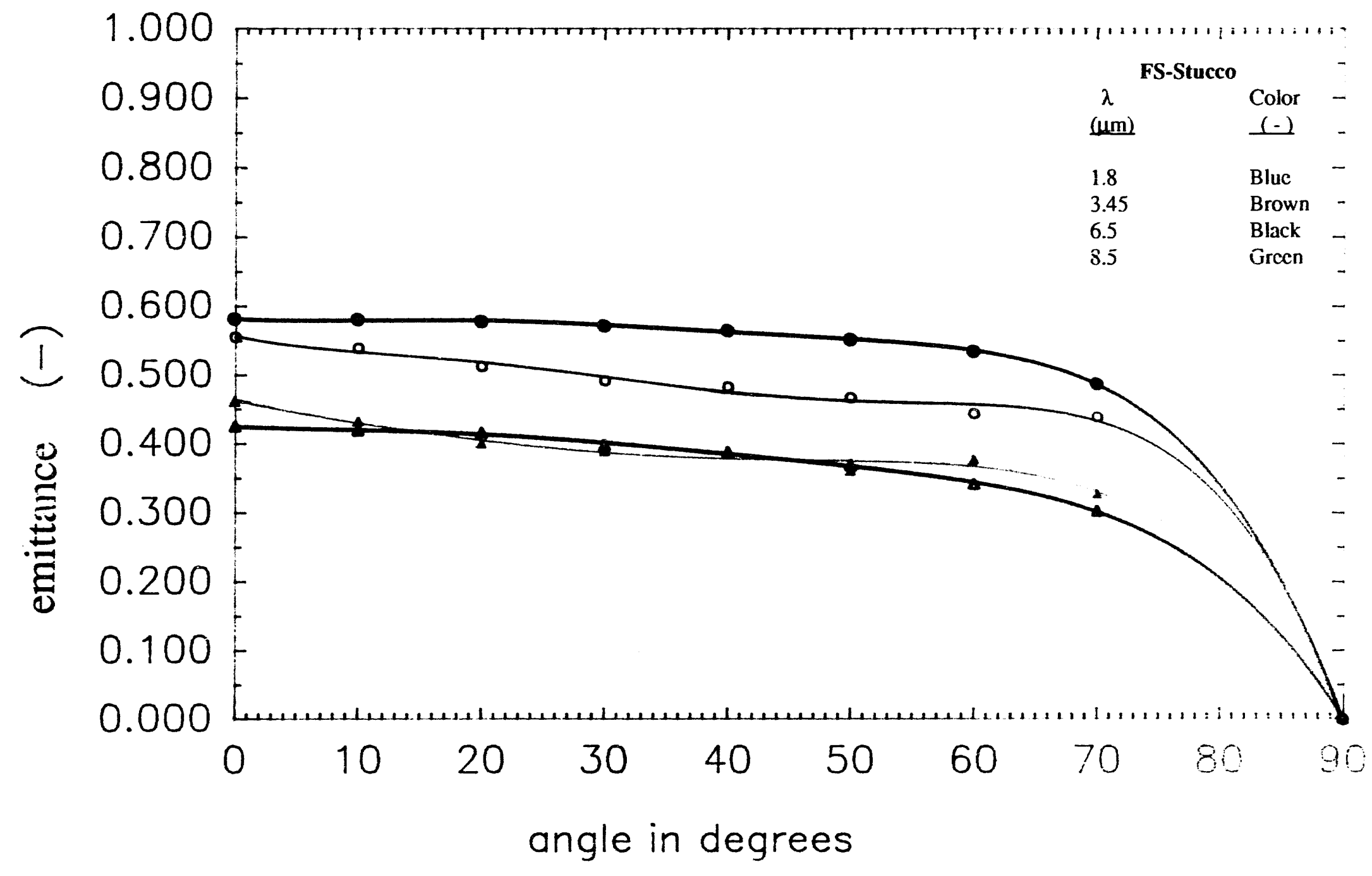

Figure 5. FS-stucco directional spectral emittance. 


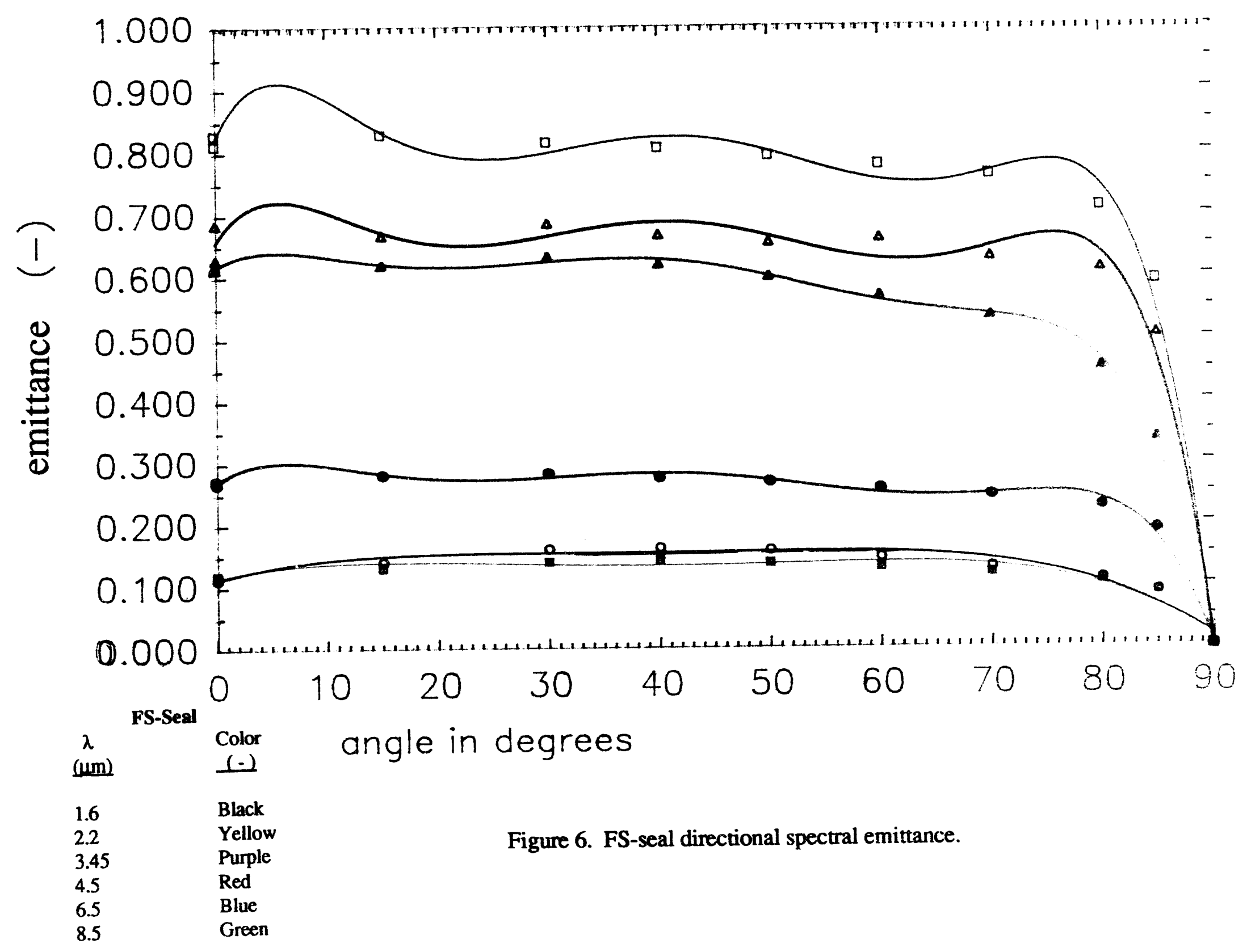



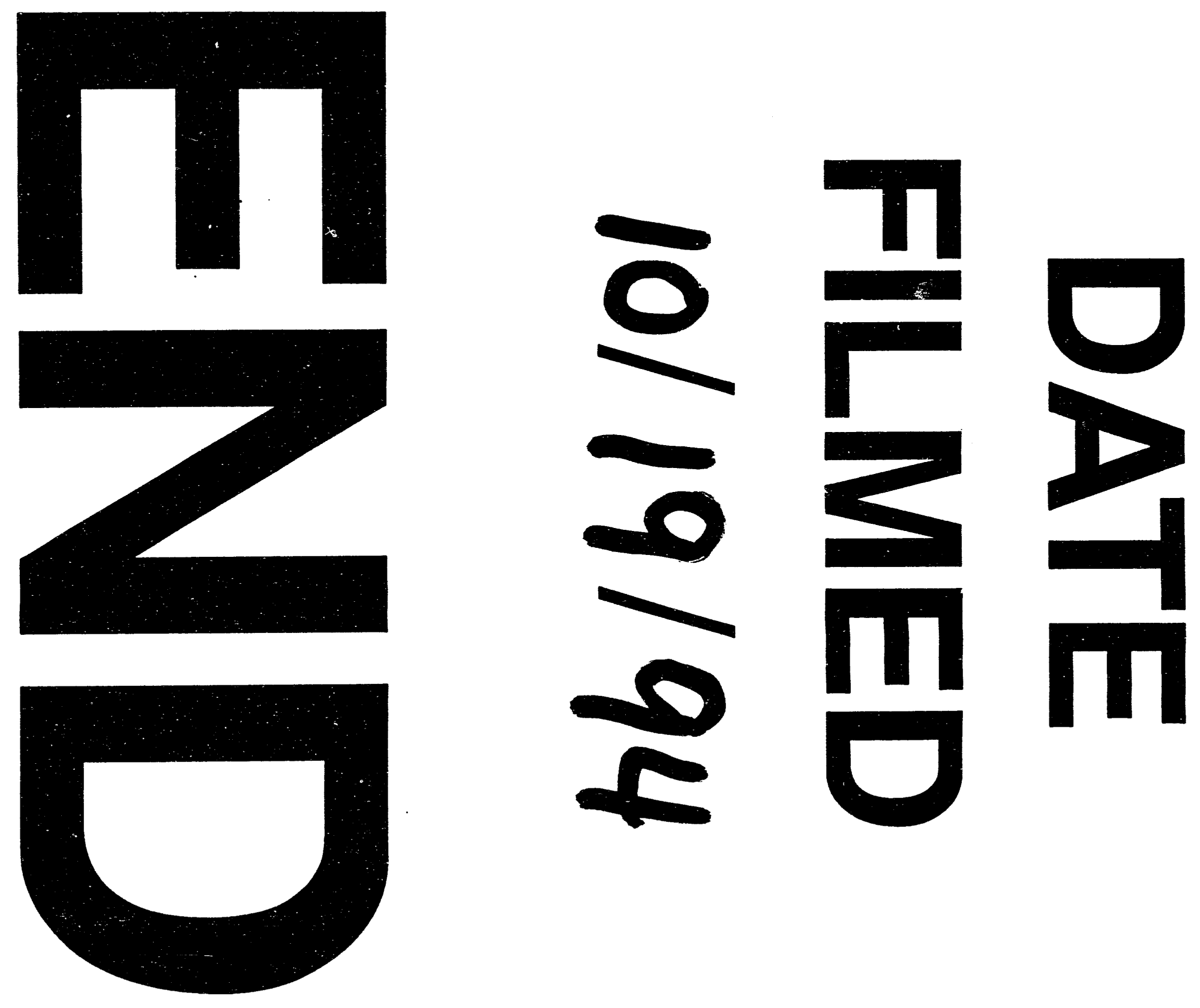


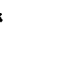

